\title{
Living donor domino liver transplantation in a hepatitis $C$ virus/human immunodeficiency virus-coinfected hemophilia patient: a case report
}

\author{
Hidekazu Yamamoto ${ }^{1 *} \mathbb{D}$, Yasuhiko Sugawara', Yuzuru Sambommatsu', Keita Shimata', Daiki Yoshii', Kaori Isono ${ }^{1}$,
} Masaki Honda ${ }^{1}$, Taro Yamashita ${ }^{2}$, Shuzo Matsushita ${ }^{3}$, Yukihiro Inomata ${ }^{4}$ and Taizo Hibi ${ }^{1}$

\begin{abstract}
Background: Outcome of the liver transplantation (LT) is worse in hepatitis C virus (HCV)/human immunodeficiency virus (HIV)-coinfected patients compared to patients infected with HCV alone. We report the world's first case of living donor domino liver transplantation (LDDLT) using a familial amyloid polyneuropathy (FAP) liver in a coinfected recipient with HCV-related liver cirrhosis.

Case presentation: The recipient was a 43-year-old male with a CD4 cell count of 52/ $\mathrm{LL}$ and undetectable HIV-RNA at the time of LT. He received a domino liver graft from a 41-year-old female with FAP. No acute cellular rejection or infection occurred after LT. HCV recurrence was confirmed histologically on the posttransplant day 34. Peginterferon/ ribavirin therapy resulted in non-response; however, the patient achieved a sustained viral response with sofosbuvir (SOF)/ledipasvir (LDV). Currently, HCV and HIV testing are negative, and symptomatic de novo amyloidosis has not occurred.
\end{abstract}

Conclusions: LDDLT allows successful LT in HCV/HIV-coinfected patients; posttransplant HCV recurrence can be successfully treated with anti-viral therapy.

Keywords: Direct-acting antivirals, HCV/HIV-coinfection, Liver transplantation, Living donor domino liver transplantation, Sofosbuvir/ledipasvir

\section{Background}

The introduction of anti-retroviral therapy (ART) has improved outcome in patients infected with the human immunodeficiency virus (HIV) $[1,2]$. In the ART era, end-stage liver disease related to hepatitis $\mathrm{C}$ virus $(\mathrm{HCV})$ and hepatitis $\mathrm{B}$ virus (HBV) coinfection has emerged as a main cause of morbidity and mortality in HIV-infected individuals; HCV- and HBV-related cirrhosis have

\footnotetext{
* Correspondence: yamahide@kuh.kumamoto-u.ac.jp

'Department of Pediatric Surgery and Transplantation, Kumamoto University Graduate School of Medical Sciences, 1-1-1, Honjo, Chuo-ku, Kumamoto 860-8556, Japan

Full list of author information is available at the end of the article
}

become the most common indication for liver transplantation (LT) among the HIV patients.

Domino liver transplantation (DLT) has been established as a tool that contributes to expansion of the donor pool. Except for the production of an abnormal protein or enzyme, these livers are morphologically normal and fully functional. However, the metabolic disease of the donor is usually transmitted to the DLT recipient several years after LT [3-5]. Patients with familial amyloid polyneuropathy (FAP) are the most common donor in DLT. In most studies of long-term outcome in DLT, FAP patients received livers from deceased donors [6-10]. Therefore the data regarding living donor domino liver transplantation 
(LDDLT) is limited [11, 12]. We report the first case of successful LDDLT in a HCV/HIV-coinfected patient

\section{Case presentation}

The patient was a 43-year-old male with HCV-related end stage liver disease (ESLD) coinfected with HIV. He was diagnosed with hemophilia $B$ at the age of 6 years and later infected with both HCV and HIV by transfusion with contaminated plasma-derived factor concentrates. Initially, he was a non-progressor for many years after HIV infection was diagnosed. However, at age 35 years, he began ART. Eight years later, his CD4 count recovery was attenuated, and the ART was changed from efavirenz to raltegravir. Subsequently, the patient developed ART-induced liver toxicity and ART was discontinued. His liver function continued to worsen due to HCV-related ESLD and became life-threatening. At this point, the patient was evaluated for liver transplantation: Laboratory tests revealed serum total bilirubin (T-Bil) $25.4 \mathrm{mg} / \mathrm{dL}$, aspartate aminotransferase (AST) $57 \mathrm{U} / \mathrm{L}$, alanine aminotransferase (ALT) $39 \mathrm{U} / \mathrm{L}$, prothrombin time-international normalized ratio (PT-INR) 1.64, activated partial thromboplastin time (APTT) $66 \mathrm{~s}$, platelet count $84 \times 10^{3} / \mu \mathrm{L}$, and factor IX $6 \%$ of standard. The inhibitor of factor IX did not develop. The HCV-RNA viral load was $5.5 \log \mathrm{IU} / \mathrm{mL}$ and genotype was $1 \mathrm{a}$. Model for end-stage liver disease (MELD) score was 24, Child-Pugh score was 10, CD4 cell count was $52 / \mu \mathrm{L}$ (CD4/CD8 ratio 0.09), and HIV-RNA was undetectable.

He received a domino liver graft from a 41-year-old female with FAP. The whole liver without inferior vena cava was transplanted using the piggy-back technique. The right hepatic vein of the liver graft was anastomosed to the stump of recipient's right hepatic vein. The unified middle and left hepatic vein of the liver graft was anastomosed to the recipient's trunk of the middle and left hepatic vein in an end-to-end fashion. The portal vein was anastomosed with the branch patch (left and right branches of the recipient's portal vein) in an endto-end fashion. After reperfusion, the hepatic artery was microsurgically reconstructed. Duct-to-duct anastomosis was employed for the biliary reconstruction. Additionally, splenectomy was performed for prevention of interferon-induced thrombocytopenia in the posttransplant treatment of hepatitis $C$. The length of operation was $11 \mathrm{~h} 30 \mathrm{~min}$. The blood loss was $2936 \mathrm{~mL}$ and a total of $569 \mathrm{~mL}$ of red cells concentrates, and $720 \mathrm{ml}$ of freshfrozen plasma was infused during transplantation. Histopathology of the explanted liver showed the findings compatible with $\mathrm{HCV}$ liver cirrhosis (necroinflammatory activity score, A3; fibrosis score, F4).

One thousand $U$ of recombinant factor was infused every 4-5 days before transplantation. Immediately before transplantation, $5000 \mathrm{U}$ of recombinant factor was given by bolus infusion, and recombinant factor was administered continuous and additional eight bolus infusion in total to keep APTT less than $45 \mathrm{~s}$ intraoperatively. After transplantation, recombinant factor was given continuously until 2 days.

Postoperatively, the patient received tacrolimus and steroids for immunosuppression; the steroids were rapidly tapered within 3 months after LT. The target trough levels of tacrolimus were 10 to $15 \mathrm{ng} / \mathrm{mL}$ through the week 2 postoperatively, and then around $10 \mathrm{ng} / \mathrm{mL}$ until 1 month postoperatively, 5 to $10 \mathrm{ng} / \mathrm{mL}$ until 3 months. The patient has remained free of both infection and acute cellular rejection since LT and liver function testing has been stable. ART consisting of emtricitabine, tenofovir, and raltegravir was reinitiated on the posttransplant day 1 . Four months after LT, the CD4 cell count gradually increased and exceeded more than $100 / \mu \mathrm{L}$ (Fig. 1a). Darunavir and ritonavir were then added, and his CD4 cell count reached 204/ $\mu \mathrm{L} 12$ months after LT. The HIV viral load was persistently negative. In terms of immunosuppression, trough level of tacrolimus was around $7.0 \mathrm{ng} / \mathrm{mL}$ by $2.0 \mathrm{mg}$ twice daily before the induction of darunavir. After the induction of darunavir, tacrolimus was then given as a single dose of $0.05 \mathrm{mg}$ every $4-7$ days due to maintaining trough level of $6.0-8.0 \mathrm{ng} / \mathrm{mL}$.

$\mathrm{HCV}$ recurrence was diagnosed histologically (necroinflammatory activity score, A1; fibrosis score, F0-1) on the posttransplant day 34 . He then received antiviral therapy consisting of peginterferon- $\alpha 2 b$ and ribavirin on the posttransplant day 41 . At the start of therapy, the HCV-RNA viral load was $7.5 \log \mathrm{IU} / \mathrm{mL}$. However, he had no response, so was changed to peginterferon- $\alpha 2 \mathrm{a}$, which he received for 6 years; HCV-RNA titers remained stable. Seven years after LT, liver biopsy showed stage F3 fibrosis and laboratory analysis revealed AST 49 U/L, ALT $32 \mathrm{U} / \mathrm{L}$, T-Bil $0.4 \mathrm{mg} / \mathrm{dL}$, and creatinine $0.96 \mathrm{mg} /$ dL. His Child-Pugh score was 6 . Peginterferon- $\alpha 2$ a was converted to sofosbuvir (SOF)/ledipasvir (LDV) (directacting antivirals (DAAs) were approved to be covered by health insurance in Japan at that time). At the start of SOF/LDV therapy, the HCV-RNA viral load was $6.0 \mathrm{log}$ $\mathrm{IU} / \mathrm{mL}$; serum HCV-RNA became undetectable 14 days after initiation of SOF/LDV. Since then, the patient has maintained a sustained viral response (SVR), and HCVRNA has remained undetectable (Fig. 1b). After the initiation of SOF/LDV therapy, transaminase was normalized and renal function kept normal.

Currently, both HCV and HIV viral loads are negative, and the patient is well at 11 years after LT. Symptomatic de novo amyloidosis has not yet occurred, although faint amyloid deposition was observed in stomach and skin biopsies at 8 and 10 years after LDDLT, respectively.

This study was approved by the ethics committee of Kumamoto University Hospital (No. 892). 


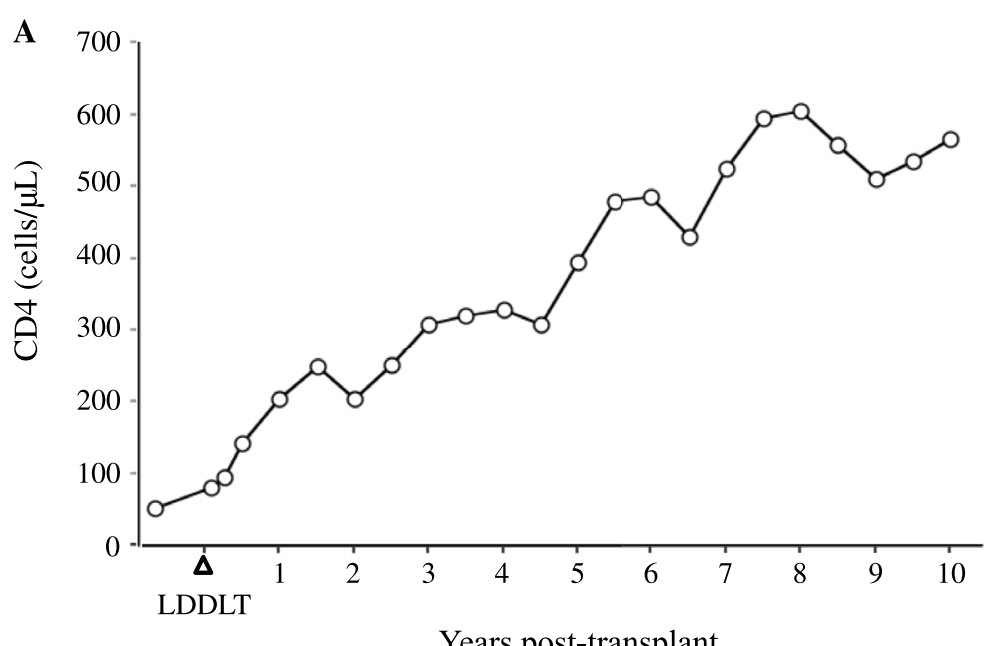

Years post-transplant
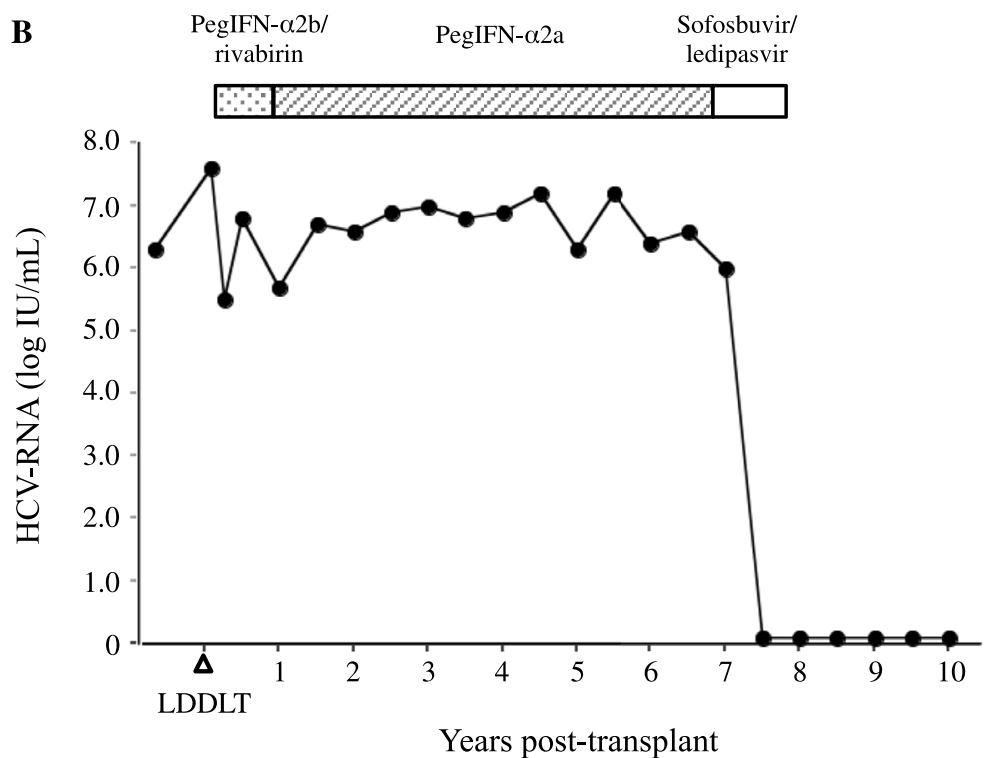

Fig. 1 a CD4 cell count following liver transplantation. LDDLT, living donor domino liver transplantation. b HCV-RNA titers following liver transplantation. Abbreviation: LDDLT, living donor domino liver transplantation

\section{Discussion}

Liver cirrhosis due to HCV/HIV-coinfection is a remarkable indication for LT. In addition, HCV/HIV-coinfected patients affected by portal hypertension when cirrhosis is absent may be considered for LT as well [13-15]. In the ART era, LT for HIV-infected patients with liver disease not related with HCV had an excellent outcome $[16,17]$. However, the outcome of LT is worse in HCV/HIV-coinfected patients than patients infected with $\mathrm{HCV}$ alone due to rapid progression of fibrosis and a higher incidence of severe recurrent HCV infection [18-20]. Therefore, it is important to consider the treatment of recurrent $\mathrm{HCV}$ after LT. One study found a significantly higher rate of progression to a fibrosis score $\geq$ F2 2 years after LT in $\mathrm{HCV} / \mathrm{HIV}$-coinfected patients (71\%) compared to patients infected with HCV alone (40\%) [18].

In previous reports, the interferon-based anti-HCV treatment for HCV/HIV-coinfected LT recipients was associated with SVR rates ranging from 11 to $27 \%[19,21,22]$. In addition, the effectiveness of DAAs against $\mathrm{HCV}$ has recently been shown for both HCV/HIV-coinfected patients and patients infected by $\mathrm{HCV}$ alone. SOF-based antiviral therapy is highly effective after LT in HCV/HIV-coinfected recipients, with SVR rates for $\mathrm{HCV}$ recurrence ranging from 89 to $100 \%$ [23-26]. In the present case, peginterferon with rivabirin was not effective in preventing recurrent 
HCV after LT. However, 14 days after SOF/LDV therapy, HCV-RNA was undetectable, and our patient achieved a SVR.

Operative criteria for LT from the point of view of HIV infection in many centers are pretransplant CD4 cell counts $>100 / \mu \mathrm{L}$ or $200 / \mu \mathrm{L}$ and absence of HIV viremia [27-29]. However, Ragni et al. reported that the critical determinant for survival was posttransplant CD4 count rather than pretransplant CD4 count [30]. Although pretransplant CD4 cell count was lower in the present case than in previously reported ones, the postoperative outcome was uneventful without infectious complications. It may be important to appropriately control immunosuppressive therapy and routinely monitor for infection.

Liver transplantation for hemophilia has a greater risk of intra- and postoperative bleeding. Several reports have discussed the efficacy of the administration of recombinant factor by continuous and/or bolus infusion as a bridge until a newly transplanted liver begins to produce and maintain adequate factor IX activity [31-33]. In this case, we could control intra-operative hemostasis well by the combination of the continuous infusion and intermittent bolus infusion with close monitoring. Additionally, our patient was given recombinant factor until 2 days posttransplant.

We have previously reported that DLT using a whole liver from a living donor liver transplantation from a FAP patient presents satisfactory results [11]. The indications for DLT included hepatocellular carcinoma (HCC), age $>50$ or 60 years, age $>40$ years with hepatitis $\mathrm{C}$ cirrhosis, and late retransplantation $[7,10]$. We believe that these were indications of DLT in case of a small number of DDLT in Japan compared with other countries. The priority was the urgency to save lives regardless of the age or the original disease of the patient. The next was one or more factors that had been set for ordinary DLT in other countries as HCC, $>50$ or 60 years of age, high MELD score, and late retransplantation. In case of such a patient, urgent LT was recommended to save life, in addition to the co-infection of $\mathrm{HCV} / \mathrm{HIV}$ that was considered to have poor prognosis compared with non-coinfected HCV. This was the reason why this patient was selected as the final candidate among the patients in the list for DDLT in our institution.

It is reported that several patients would develop the amyloidosis 3 years after DLT earliest [34]. Rodrigues et al. reported that 10 of 81 FAP liver recipients eventually required retransplantation due to de novo amyloidosis [35]. Fortunately, symptomatic de novo amyloidosis has not occurred in our patient in the 11 years since LT. Despite the risk of amyloidosis, we believe that DLT using FAP livers is a viable option given today's shortage of liver donors.

\section{Conclusions}

We report the world's first case of LDDLT in a HCV/ HIV-coinfected who was a long survivor. DLT with a FAP liver can be a treatment option for liver cirrhosis associated with HCV/HIV-coinfection, although de novo amyloidosis may later occur in the recipient. DAA therapy for recurrent $\mathrm{HCV}$ after $\mathrm{LT}$ is safe and effective in HCV/HIV-coinfected patients.

\section{Abbreviations \\ ART: Anti-retroviral therapy; HIV: Human immunodeficiency virus; HCV: Hepatitis C; HBV: Hepatitis B; LT: Liver transplantation; DLT: Domino liver transplantation; FAP: Familial amyloid polyneuropathy; LDDLT: Living donor domino liver transplantation; ESLD: End stage liver disease; T-Bil: Total bilirubin; AST: Aspartate aminotransferase; ALT: Alanine aminotransferase; PT: Prothrombin time-international normalized ratio; APTT: Activated partial thromboplastin time; MELD: Model for End-stage Liver Disease; SOF/ LDV: Sofosbuvir/ledipasvir; DAAs: Direct-acting antivirals; SVR: Sustained viral response; HCC: Hepatocellular carcinoma}

\section{Acknowledgements}

The authors would like to thank Professor Susumu Eguchi (Department of Surgery, Nagasaki University Graduate School of Biomedical Sciences) and all members of the research group on HIV/AIDS from the Ministry of Health, Labor, and Welfare of Japan (the Eguchi project) for their encouragement, continuous support, and motivation.

\section{Authors' contributions}

All authors conceived of the study and participated in its design and coordination and helped to draft the manuscript. All authors read and approved the final manuscript.

\section{Funding}

This study was not funded.

Ethics approval and consent to participate

This present study was conducted in accordance with the ethical standards of Kumamoto University Hospital.

Consent for publication

Consent to publish was obtained from the patient.

\section{Competing interests}

The authors declare that they have no competing interests.

\section{Author details}

'Department of Pediatric Surgery and Transplantation, Kumamoto University Graduate School of Medical Sciences, 1-1-1, Honjo, Chuo-ku, Kumamoto 860-8556, Japan. ${ }^{2}$ Department of Neurology, Kumamoto University Graduate School of Medical Sciences, Kumamoto 860-8556, Japan. ${ }^{3}$ Center for AIDS Research, Kumamoto University, Kumamoto 860-8556, Japan. ${ }^{4}$ Department of Surgery, Kumamoto Rosai Hospital, Kumamoto 866-8533, Japan.

Received: 13 May 2020 Accepted: 15 July 2020

Published online: 29 July 2020

References

1. Palella FJ Jr, Delaney KM, Moorman AC, Loveless MO, Fuhrer J, Satten GA, et al. Declining morbidity and mortality among patients with advanced human immunodeficiency virus infection. HIV Outpatient Study Investigators. N Engl Med. 1998;338:853-60.

2. Mocroft A, Katlama C, Johnson AM, Pradier C, Antunes F, Mulcahy F, et al. AIDS across Europe, 1994-98: the EuroSIDA study. Lancet. 2000;356:291-6.

3. Stangou AJ, Heaton ND, Hawkins PN. Transmission of systemic transthyretin amyloidosis by means of domino liver transplantation. N Engl Med. 2005; 352:2356.

4. Ericzon BG, Larsson M, Wilczek HE. Domino liver transplantation: risks and benefits. Transplant Proc. 2008:40:1130-1. 
5. Misumi Y, Narita Y, Oshima T, Ueda M, Yamashita T, Tasaki M, et al. Recipient aging accelerates acquired transthyretin amyloidosis after domino liver transplantation. Liver Transpl. 2016;22:656-64.

6. Stangou AJ, Heaton ND, Rela M, Pepys MB, Hawkins PN, Williams R. Domino hepatic transplantation using the liver from a patient with familial amyloid polyneuropathy. Transplantation. 1998:65:1496-8.

7. Yamamoto S, Ericzon BG. Domino liver transplantation as a valuable option. Transpl Int. 2014;27:e27-8.

8. Escobar B, Taura P, Barreneche N, Beltran J, Balust J, Martinez-Palli G, et al. The influence of the explant technique on the hemodynamic profile during sequential domino liver transplantation in familial amyloid polyneuropathy patients. Liver Transpl. 2009;15:869-75.

9. Tincani G, Hoti E, Andreani P, Ricca L, Pittau G, Vitale V, et al. Operative risks of domino liver transplantation for the familial amyloid polyneuropathy liver donor and recipient: a double analysis. Am J Transplant. 2011;11:759-66.

10. Bispo M, Marcelino P, Marques HP, Martins A, Perdigoto R, Aguiar MJ, et al. Domino versus deceased donor liver transplantation: association with early graft function and perioperative bleeding. Liver Transpl. 2011;17:270-8.

11. Inomata Y, Zeledon ME, Asonuma K, Okajima H, Takeichi T, Ishiko T, et al. Whole-liver graft without the retrohepatic inferior vena cava for sequential (domino) living donor liver transplantation. Am J Transplant. 2007;7:1629-32.

12. Asonuma K, Ohya Y, Isono K, Takeichi T, Yamamoto H, Lee KJ, et al. Current state of domino transplantation in Japan in terms of surgical procedures and de novo amyloid neuropathy. Amyloid. 2012;19:75-7.

13. Eguchi S, Takatsuki M, Soyama A, Hidaka M, Nakao K, Shirasaka T, et al. Analysis of the hepatic functional reserve, portal hypertension, and prognosis of patients with human immunodeficiency virus/hepatitis $C$ virus coinfection through contaminated blood products in Japan. Transplant Proc. 2014;46:736-8.

14. Takatsuki M, Soyama A, Eguchi S. Liver transplantation for HIV/hepatitis C virus co-infected patients. Hepatol Res. 2014;44:17-21.

15. Yoshimoto T, Eguchi S, Natsuda K, Hidaka M, Adachi T, Ono S, et al. Relationship between various hepatic function scores and the formation of esophageal varices in patients with HIV/hepatitis C virus co-infection due to contaminated blood products for hemophilia. Hepatol Res. 2019;49:147-52.

16. Tateo M, Roque-Afonso AM, Antonini TM, Medja F, Lombes A, Jardel C, et al. Long-term follow-up of liver transplanted HIV/hepatitis B virus coinfected patients: perfect control of hepatitis B virus replication and absence of mitochondrial toxicity. AIDS. 2009;23:1069-76.

17. Coffin CS, Stock PG, Dove LM, Berg CL, Nissen NN, Curry MP, et al. Virologic and clinical outcomes of hepatitis B virus infection in HIV-HBV coinfected transplant recipients. Am J Transplant. 2010;10:1268-75.

18. Duclos-Vallee JC, Feray C, Sebagh M, Teicher E, Roque-Afonso AM, Roche B, et al. Survival and recurrence of hepatitis $C$ after liver transplantation in patients coinfected with human immunodeficiency virus and hepatitis $C$ virus. Hepatology. 2008;47:407-17.

19. de Vera ME, Dvorchik I, Tom K, Eghtesad B, Thai N, Shakil O, et al. Survival of liver transplant patients coinfected with HIV and HCV is adversely impacted by recurrent hepatitis C. Am J Transplant. 2006:6:2983-93.

20. Manzardo C, Londono MC, Castells L, Testillano M, Luis Montero J, Peñafie J, et al. Direct-acting antivirals are effective and safe in HCV/HIV-coinfected liver transplant recipients who experience recurrence of hepatitis $\mathrm{C}$ : a prospective nationwide cohort study. Am J Transplant. 2018;18:2513-22.

21. Duclos-Vallee JC, Vittecoq D, Teicher E, Feray C, Roque-Afonso AM, Lombès $A$, et al. Hepatitis $C$ virus viral recurrence and liver mitochondrial damage after liver transplantation in HIV-HCV co-infected patients. J Hepatol. 2005; 42:341-9.

22. Castells L, Rimola A, Manzardo C, Valdivieso A, Montero JL, Barcena R, et al. Pegylated interferon plus ribavirin in HIV-infected patients with recurrent hepatitis C after liver transplantation: a prospective cohort study. J Hepatol. 2015;62:92-100.

23. Londono MC, Manzardo C, Rimola A, Ruiz P, Costa J, Forner A, et al. IFN-free therapy for HIV/HCV-coinfected patients within the liver transplant setting. J Antimicrob Chemother. 2016:71:3195-201.

24. Campos-Varela I, Moreno A, Morbey A, Guaraldi G, Hasson H, Bhamidimarri $K R$, et al. Treatment of severe recurrent hepatitis $C$ after liver transplantation in HIV infected patients using sofosbuvir-based therapy. Aliment Pharmacol Ther. 2016:43:1319-29.

25. Castells L, Llaneras J, Campos-Varela I, Bilbao I, Crespo M, Len O, et al. Sofosbuvir and daclatasvir in mono- and HIV-coinfected patients with recurrent hepatitis C after liver transplant. Ann Hepatol. 2017;16:86-93.
26. Antonini TM, Coilly A, Rossignol E, Fougerou-Leurent C, Dumortier J, Leroy $V$, et al. Sofosbuvir-based regimens in HIV/HCV coinfected patients after live transplantation: results from the ANRS CO23 CUPILT study. Transplantation. 2018;102:119-26.

27. O'Grady J, Taylor C, Brook G. Guidelines for liver transplantation in patients with HIV infection (2005). HIV Med. 2005;6:149-53.

28. Guaraldi G, Dolci G, Zona S, Tarantino G, Serra V, Ballarin R, et al. A frailty index predicts post-liver transplant morbidity and mortality in HIV-positive patients. AIDS Res Ther. 2017;14:37.

29. Blumberg EA, Rogers CC, American Society of Transplantation Infectious Diseases Community of P. Solid organ transplantation in the HIV-infected patient: guidelines from the American Society of Transplantation Infectious Diseases Community of Practice. Clin Transpl. 2019;33:e13499.

30. Ragni MV, Belle SH, Im K, Neff G, Roland M, Stock P, et al. Survival of human immunodeficiency virus-infected liver transplant recipients. J Infect Dis. 2003;188:1412-20

31. Lambing A, Kuriakose P, Kachalsky E. Liver transplantationin the haemophilia patient. Haemophilia. 2012;18:300-3.

32. Yokoyama S, Bartlett A, Dar FS, Heneghan M, O'Grady J, Rela M, et al. Outcome of liver transplantation for haemophilia. HPB (Oxford). 2011;13:40-5.

33. Togashi J, Akamatsu N, Tanaka T, Sugawara Y, Tsukada K, Kaneko J, et al. Living donor liver transplantation for hemophilia with special reference to the management of perioperative clotting factor replacement. Liver Transpl. 2016:22:366-70.

34. Sousa MM, Ferrao J, Fernandes R, Guimaraes A, Geraldes JB, Perdigoto R, et al. Deposition and passage of transthyretin through the blood-nerve barrier in recipients of familial amyloid polyneuropathy livers. Lab Investig. 2004;84:865-73.

35. Rodrigues C, Vieira H, Jesus J, Pereira L, Bento C, Seco C, et al. Evaluation of operative risk in de novo familial amyloid polyneuropathy retransplantation. Transplant Proc. 2015;47:1016-8.

\section{Publisher's Note}

Springer Nature remains neutral with regard to jurisdictional claims in published maps and institutional affiliations.

\section{Submit your manuscript to a SpringerOpen ${ }^{\circ}$ journal and benefit from:}

- Convenient online submission

- Rigorous peer review

- Open access: articles freely available online

- High visibility within the field

- Retaining the copyright to your article

Submit your next manuscript at $>$ springeropen.com 